\title{
A DISCIPLINA DE BIOLOGIA NAS DIRETRIZES CURRICULARES DO PARANÁ
}

\author{
Cibele Franzoi Silva Souza ${ }^{1}$, José Nunes dos Santos ${ }^{2}$, Maria Júlia Corazza ${ }^{1}$ \\ ${ }^{1}$ Universidade Estadual de Maringá - UEM, Programa de Pós-Graduação do PCM, Maringá, PR. ${ }^{2}$ Universidade Estadual \\ de Campinas - UNICAMP, Campinas, SP. E-mail: cibele.franzoi@gmail.com
}

\section{RESUMO}

Este artigo compõe-se de uma breve análise das Diretrizes Curriculares do Ensino de Biologia (DCEs) do Estado do Paraná. Tem como objetivo identificar as abordagens do encaminhamento metodológico dessa diretriz na qualificação do processo e ensino-aprendizagem. Optamos por uma pesquisa qualitativa, mediante revisão da literatura. A concepção de currículo proposta na DCEs para o ensino de Biologia está justificada com base nas teorias críticas fundamentada ao materialismo histórico dialético, considerando as dimensões científica, filosófica e artística, enfatizando-se a importância de todas as disciplinas. De acordo com as DCEs (Paraná, 2008a), os conteúdos básicos e específicos de Biologia são subsidiados pelos conteúdos estruturantes: organização dos seres vivos, mecanismos biológicos, sistemas biológicos, biodiversidade e manipulação genética. O conteúdo específico da disciplina de Biologia selecionado pelo professor para cada série deve ocorrer de forma integrada, ou seja, sofrer a influência do contexto social, histórico e econômico em que o aluno está inserido.

Palavras-chave: Diretrizes curriculares. Ensino de biologia. Método de ensino. Ensinoaprendizagem.

\section{THE BIOLOGY DISCIPLINE IN THE CURRICULUM GUIDELINES OF PARANÁ}

\begin{abstract}
This article consists of a brief analysis of the Curriculum Guidelines for Teaching Biology (DCEs) of Paraná. It aims to identify the methodological approaches to routing of this guideline in the teaching process and learning. We have chosen a qualitative research through literature review. The proposed curriculum's concept in DCEs for teaching Biology is justified based on critical theories based on historical dialectic materialism, considering the scientific, philosophical and artistic dimensions, emphasizing the importance of all disciplines. According to the DCEs (Paraná, 2008a), the basic and specific contents of Biology are subsidized by structuring content: organization of living things, biological mechanisms, biological systems, biodiversity and genetic manipulation. The specific content of Biology selected by the teacher for each grade should occur in an integrated manner, free from the influence of the social, historical, economic, and the student is inserted.
\end{abstract}

Keywords: Curriculum Guidelines. Teaching Biology. Teaching method. Process and learning. 
INTRODUÇÃO

A qualidade do ensino básico é um dos requisito fundamentais para a inserção e democratização das oportunidades educacionais, mas esta perspectiva constitui-se em um dos maiores desafios para a educação brasileira. Porém, a consolidação de uma prática pedagógica de qualidade é trabalho de todos, e a disciplina de Biologia faz parte desta organização de ensino.

A Lei de Diretrizes e Bases da Educação (LDB) № 9394/96 determina e legitima o sistema de educação em todos os estados do território do Brasil. A lei, fundamentada nos princípios presentes na Constituição Federal de 1988 e publicada em dezembro de 1996, instituiu as Diretrizes e Bases para a Educação Nacional, a partir das quais foram elaborados os Parâmetros Curriculares Nacionais (PCN) em âmbito federal (BRASIL, 1998) e as Diretrizes Curriculares Estaduais (DCEs) da Secretaria de Estado da Educação (SEED) do Estado do Paraná.

Em 2003, muitos docentes do ensino de Biologia foram nomeados para o quadro próprio do magistério da SEED do Estado do Paraná. A escola pública neste período estava sendo reformulada no Estado do Paraná,ancorada por um intenso debate acerca das concepções teórico-metodológicas para as diferentes disciplinas que compõem a matriz curricular da educação básica. Debates esses que possibilitavam reflexões para a organização do ensino, assinalando o docente como sujeito epistêmico e a escola como local fundamental para as discussões que e nortearam os apontamentos e sugestões para a edificação das DCEs para as diferentes disciplinas de ensino.

A Secretaria de Estado da Educação, entre os anos de 2004 a 2006, possibilitou simpósios e seminários aos docentes possibilitando uma aproximação inicial para a preparação das DCEs. Assim, os professores de Biologia procuraram auxílios em encontros e semanas de estudos pedagógicos para compreender o processo de elaboração dos textos das Diretrizes Curriculares para o ensino de Biologia.

A partir de 2007 e 2008, a coordenação e equipe pedagógica do Departamento de Educação Básica da SEED percorreram os Núcleos Regionais de Educação do Estado do Paraná realizando o evento DEB itinerante que proporcionou para docentes da rede estadual de ensino, cursos de formação continuada (PARANÁ, 2008a). Esses cursos de formação continuada apresentavam caráter disciplinar e tiveram o objetivo de apresentar os fundamentos teóricos das DCEs quanto aos aspectos metodológicos de sua implementação para o ensino. Em meados de 2008, finalizaram-se os debates para a construção da Diretriz Curricular para o ensino de Biologia, que foi escrita e publicada no final desse mesmo ano. 
Para a seleção do conhecimento escolar, o ensino de Biologia é auxiliado pelos conteúdos disciplinares, isto é, conteúdos escolares (conteúdos estruturantes ${ }^{1}$ e básicos ${ }^{2}$ ), e que tais conteúdos podem ser ensinados a partir da mediação didática estabelecida por estratégias que procurem situar relações interdisciplinares e contextuais (PARANÁ, 2008a).

Desta forma, os PCNs que norteavam o ensino da educação do Estado do Paraná foram substituídos pelas Diretrizes Curriculares Estaduais, que trazem orientações para o ensino das diversas disciplinas da Educação Básica (Paraná, 2008b).

Este artigo compõe-se de uma breve análise da Diretriz Curricular para o ensino de Biologia para a Rede Pública Estadual do Paraná e tem como objetivo identificar as abordagens teóricas que norteiam o encaminhamento metodológico dessa diretriz e sua contribuição para a qualificação do processo e ensino-aprendizagem.

\section{METODOLOGIA}

O trabalho consiste de uma pesquisa qualitativa, descritiva e documental. A pesquisa documental assemelha-se muito à pesquisa bibliográfica, "as fontes bibliográficas nada mais são do que documentos impressos para determinado público" (GIL, 2002, p.46) Desta forma, a consulta bibliográfica permite informações científicas e culturais, dentre outras, por meio do referencial teórico publicados sobre um determinado assunto.

A pesquisa qualitativa em Educação possibilita analisar uma situação natural, coletar dados descritivos e analisar a "realidade de forma complexa e contextualizada", "sem qualquer manipulação intencional do pesquisador' (LÜDKE e ANDRÉ, 1986, p.11 -18). Assim, utilizamos as Diretrizes Curriculares do ensino de Biologia da Rede Pública Estadual do Paraná como instrumento de análise para responder aos objetivos deste trabalho e algumas questões de pesquisa.

No presente trabalho, para nortear a pesquisa, estabelecemos os seguintes questionamentos: Quais métodos presentes nas diretrizes subsidiam o ensino de Biologia? Quais as relações existentes entre os argumentos metodológicos e teorias (teórico-metodológicos)? Como estabelecer a seleção de conteúdos a serem trabalhados em sala de aula e que possibilitam a construção social do conhecimento?

\footnotetext{
${ }^{1}$ Conteúdos estruturantes são os saberes, conhecimentos de grande amplitude, que identificam e organizam os campos de estudos de uma disciplina escolar, considerados fundamentais para as abordagens pedagógicas dos conteúdos específicos e conseqüente compreensão de seu objeto de estudo e ensino (PARANÁ, 2008a, p. 55).

2 Entende-se por conteúdos básicos os conhecimentos fundamentais para cada série da etapa final do ensino fundamental e para o ensino médio, considerados imprescindíveis para a formação conceitual dos estudantes nas diversas disciplinas da educação Básica (PARANÁ, 2008a, p. 73). 


\section{DISCUSSÃO}

A partir da proposta pedagógica curricular para o ensino de Biologia da Rede Pública Estadual do Paraná, efetuamos um recorte na fundamentação teórica - argumentos dos textos presentes nas Diretrizes Curriculares do Ensino de Biologia, destacando o pensamento metodológico, isto é, os comentários e fundamentações das teorias básicas relacionadas ao método e teorias que contribuem para a aprendizagem de biologia. Ressaltamos: a) 0 método, b) encaminhamentos metodológicos e c) Teóricos.

Quadro1. Métodos, encaminhamentos metodológicos e ênfase dos Teóricos

\begin{tabular}{|c|c|c|}
\hline Métodos & Encaminhamentos metodológicos & Teóricos \\
\hline $\begin{array}{l}\text { Para o ensino de biologia, } \\
\text { propõe-se o método da } \\
\text { prática social, que decorre } \\
\text { das relações dialéticas entre } \\
\text { conteúdo de ensino e } \\
\text { concepção de mundo } \\
\text { (LIBÂNEO, 1983; SAVIANI, } \\
\text { 1997, apud PARANÁ, 2008, } \\
\text { p.54). }\end{array}$ & $\begin{array}{l}\text { - prática social: se caracteriza como } \\
\text { ponto de partida, cujo objetivo é } \\
\text { perceber e denotar, dar significação } \\
\text { às concepções alternativas do aluno a } \\
\text { partir de uma visão sincrética, } \\
\text { desorganizada, de senso comum a } \\
\text { respeito do conteúdo; } \\
\text { - a problematização: implica o } \\
\text { momento para detectar e apontar as } \\
\text { questões a serem resolvidas na } \\
\text { prática social; } \\
\text { - a instrumentalização: consiste em } \\
\text { apresentar os } \\
\text { sistematizados para que os alunos } \\
\text { assimilem e os transformem em } \\
\text { instrumentos de construção pessoal } \\
\text { e profissional; } \\
\text { - a catarse: a fase de aproximação } \\
\text { entre o conhecimento adquirido pelo } \\
\text { aluno e o problema em questão; } \\
\text { - o retorno a prática social: se } \\
\text { caracteriza pela apropriação do saber } \\
\text { concreto e pensando para atuar e } \\
\text { transformar as relações de produção } \\
\text { que impedem a construção de uma } \\
\text { sociedade igualitária (SAVIANI, 1997; } \\
\text { GASPARIN, 2003, apud PARANÁ, } \\
\text { 2008, p. 64). }\end{array}$ & $\begin{array}{l}\text { LIBÂNEO (1983) } \\
\text { SAVIANI (1997) } \\
\text { GASPARIN (2002) }\end{array}$ \\
\hline
\end{tabular}

Fonte: Própria.

O papel do professor é possibilitar que o conhecimento seja adquirido, por meio de métodos que podem estimular a atividade e iniciativa dos alunos, sem abrir mão, porém, da 
iniciativa do professor, favorecendo diálogo dos alunos entre si e com o professor, mas sem deixar de valorizar o diálogo com a cultura acumulada historicamente (SAVIANI, 1997).

Portanto, a educação com qualidade social implica na garantia do direito à educação para todos, por meio de políticas públicas, programas e ações articuladas, para a melhoria dos processos de organização e gestão do sistema escolar, privilegiando a construção da qualidade social inerente ao processo educativo (SANTOS, 2011). Para um ensino que possibilite um processo de aprendizagem significativa é preciso levar em conta a proposta pedagógica curricular (PPC), projeto político pedagógico (PPP) que subsidia todo trabalho docente. Desta forma, o professor necessita ter muita clareza sobre quais são os objetivos dos conteúdos, das estratégias pedagógicas a serem utilizadas e que tendência pedagógica fundamenta e norteia o ensino.

De acordo com as DCEs (Paraná, 2008a), os conteúdos básicos e específicos de Biologia são subsidiados pelos conteúdos estruturantes: organização dos seres vivos, mecanismos biológicos, sistemas biológicos, biodiversidade e manipulação genética. Desse modo, o conteúdo específico da disciplina de Biologia selecionado pelo professor para cada série deve ocorrer de forma integrada, ou seja, sofrer a influência do contexto social, histórico e econômico em que o aluno está inserido.

Para cada conteúdo estruturante, as Diretrizes das escolas públicas do Paraná propõem trabalhar os seguintes aspectos:

Quadro2. Conteúdos estruturantes

\begin{tabular}{|c|c|}
\hline Conteúdos estruturantes & Aspectos \\
\hline Organização dos Seres Vivos & $\begin{array}{l}\text { "O trabalho pedagógico neste conteúdo estruturante deve } \\
\text { ser permeado por uma concepção metodológica que permita } \\
\text { abordar a classificação dos seres vivos como uma das } \\
\text { tentativas de conhecer e compreender a diversidade biológica } \\
\text { considerando, inclusive, a história da vida" (PARANÁ, 2008, } \\
64)\end{array}$ \\
\hline Mecanismos Biológicos & $\begin{array}{l}\text { "Neste conteúdo estruturante é importante que o professor } \\
\text { consiste o aprofundamento, a especialização e o } \\
\text { conhecimento objetivo dos mecanismos biológicos" (PARANÁ, } \\
2008, \text { p. 65). }\end{array}$ \\
\hline Biodiversidade & $\begin{array}{l}\text { "Nestas Diretrizes, pretende-se que as reflexões propostas } \\
\text { pelo trabalho pedagógico neste conteúdo sejam permeadas } \\
\text { por uma concepção metodológica que permita abordar as } \\
\text { contribuições de Lamarck e Darwin para superar as ideias } \\
\text { fixistas já superadas há muito pela ciência e supostamente } \\
\text { pela sociedade" (PARANÁ, 2008, p. 65). }\end{array}$ \\
\hline Manipulação Genética & $\begin{array}{l}\text { "Ao manipular este conteúdo estruturante pretende-se que o } \\
\text { trabalho pedagógico seja permeado por uma concepção } \\
\text { metodológica que permita a análise sobre as implicações dos } \\
\text { avanços biológicos que se valem das técnicas de manipulação }\end{array}$ \\
\hline
\end{tabular}


do material genético para o desenvolvimento da sociedade (PARANÁ, 2008, p. 65).

Fonte: Própria.

Encontramos nas DCEs de ensino de biologia uma tendência pedagógica fundamentada na Teoria Histórico Cultural (psicologia histórico cultural) e Pedagogia Histórico-Crítica (Pedagogia Crítica Social dos Conteúdos); nos encaminhamentos metodológicos na perspectiva didática desta pedagogia o ensino de Biologia pode ser organizado com o auxilio das seguintes abordagens e estratégias de ensino:

Quadro 3. Abordagens e estratégias para que o estudante se aproprie de conceitos

\begin{tabular}{|l|l|}
\hline Abordagens & Estratégias \\
\hline Problematização & $\begin{array}{l}\text { “Utilizar a problematização como abordagem no } \\
\text { desenvolvimento dos quatro conteúdos estruturantes" } \\
\text { (PARANÁ, 2008, p. 65). }\end{array}$ \\
\hline Relação interdisciplinar & $\begin{array}{l}\text { "A interdisciplinaridade está relacionada ao conceito sócio- } \\
\text { histórico como princípio integrador do currículo" (PARANÁ, } \\
\text { 2008, p. 28). }\end{array}$ \\
\hline Aula dialogada & $\begin{array}{l}\text { "Esse processo acarreta o encontro e o confronto das } \\
\text { diferentes ideias propagadas em sala de aula" (PARANÁ, } \\
\text { 2008, p. 66). }\end{array}$ \\
\hline Experimentação & $\begin{array}{l}\text { "O experimento como recurso de ensino para uma visão } \\
\text { crítica dos conhecimentos da biologia, sem a preocupação de } \\
\text { busca de resultados único" (PARANÁ, 2008, p. 52) }\end{array}$ \\
\hline
\end{tabular}

Fonte: Própria.

No processo pedagógico, as Diretrizes Curriculares para o ensino de Biologia sugere a problematização como estratégia no desenvolvimento dos conteúdos, parte do principio da mobilização do alunado na procura por conhecimentos indispensáveis para resolver problemas. Estes problemas incluem os conteúdos da Biologia ao dia-a-dia do alunado para que ele procure agir na sociedade de maneira crítica. Recomenda-se ainda, o método experimental como recurso de ensino para uma visão crítica dos conhecimentos biológicos, sem a apreensão da procura de resultados únicos.

A interdisciplinaridade nas DCEs como abordagem metodológica no desenvolvimento dos conteúdos do ensino de Biologia, corresponde à necessidade de superar a visão fragmentadora de produção de conhecimento, bem como permitir o dialogo entre as diferentes disciplinas que compõem a matriz curricular da educação básica.

Outra estratégia de ensino, apresentada nas DCEs é a aula dialogada que favorece a expressão dos alunos em sala de aula, pois esse processo ocasiona o encontro e o confronto das 
diferentes ideias propagadas durante os debates. A troca de informações entre o professor e os grupos que compartilham da aula é, portanto, a manifestação de novas interpretações.

\section{CONSIDERAÇOES FINAIS}

Os docentes da disciplina de Biologia acompanharam a elaboração das Diretrizes Curriculares para o Ensino de Biologia, compreendendo sua importância não somente para a obtenção do conhecimento propriamente dito, mas, especialmente, para o desenvolvimento de uma proposta norteadora para o ensino de Biologia, que a Secretaria de Estado da Educação do Paraná ainda não tinha. A partir de então, especialmente para a organização do planejamento escolar, tornou-se compreensível que tendência pedagógica e que encaminhamentos pedagógicos poderiam ser empregados para nortear o ensino de Biologia.

Assim, essas Diretrizes Curriculares do ensino de Biologia é fruto de um extenso processo de debate coletivo, que envolveu professores da educação básica e de nível superior, pedagogos e diretores da Rede Estadual de Ensino e, até o momento, se apresentam como documentos que fundamentam e orientam o trabalho pedagógico da disciplina de Biologia nas escolas públicas do Paraná.

Nesta perspectiva, as Diretrizes Curriculares para o ensino de Biologia proporciona aos docentes, das diferentes instituições educacionais do Estado do Paraná, alternativas de estratégias didático-pedagógicas e método de ensino capazes de subsidiar encaminhamentos pedagógicos que norteiam a formação dos educandos, na intenção de aprendizagem de conteúdos que podem ser necessários no desenvolvimento de suas capacidades, de modo a compreenderem e intervirem nos fenômenos sociais e culturais por meio da apropriação/construção de conhecimentos significativos.

\section{REFERÊNCIAS}

BRASIL. Secretaria de Educação Fundamental. Parâmetros curriculares nacionais: Ciências Naturais/Secretaria de Educação Fundamental. Brasília: MEC /SEF, 1998.

BRASIL. Lei de Diretrizes e Bases da Educação Nacional (Lei 9394/96). Brasília: Gráfica Oficial, 1996.

GASPARIN, J. L. Uma didática para a pedagogia histórico-crítica. Campinas: Autores Associados, 2002.

Gil, A. C. Como elaborar projetos de pesquisa. São Paulo : Atlas, 2002.

LIBÂNEO, J. C. Tendências pedagógicas na prática escolar. Revista da Ande. n. 6, p.11 - 19, 1983. 
LÜDKE, M.; ANDRÉ, M. Pesquisa em educação: abordagens qualitativas. São Paulo: EPU, 1986.

PARANÁ. Secretaria de Estado da Educação do Paraná. Diretrizes Curriculares da Educação Básica. Curitiba: SEED/SUED. 2008b.

PARANÁ. Secretaria de Estado da Educação do Paraná. Diretrizes Curriculares de Biologia. Curitiba: SEED/SUED, 2008a.

SAVIANI, D. Pedagogia histórico-crítica: primeiras aproximações. Campinas: Autores Associados, 1997.

SANTOS, J. N. Ensinar Ciências: reflexões sobre a prática pedagógica no contexto educacional. Blumenau: Nova Letra, 2011. 